\title{
SUBPROJETO DE HISTÓRIA NO PIBID DA UFFS: EXPERIÊNCIAS DE 2018-2019
}

| | | | | | | | | | | | | | | | | | | | | | | | | | | | | | | | | | | | | | | | | | | | | | | | | | | | | | | | | | | | | | | | | | | | | | | | | | | | | | | | | | | | | | | | | | | | | | | | | | | | | | | | | | | | | | | | | | | | | | | | | | | | | | | | | | |

\author{
Délcio Marquetti ${ }^{1}$ \\ Isabel Rosa Gritti ${ }^{2}$ \\ Renato Viana Boy
}

\section{RESUMO}

O Subprojeto de História do Programa Institucional de Bolsas de Iniciação à Docência (PIBID), na Universidade Federal da Fronteira Sul (UFFS) (Edital 07/2018), iniciou suas atividades em agosto de 2018, devendo concluí-las em fevereiro de 2020. Dentre os objetivos do Programa, destaca-se o de inserir os estudantes das licenciaturas nas escolas de Ensino Básico, espaço privilegiado de sua futura atuação, já nos primeiros anos de seu ingresso na graduação. O subprojeto divide-se em dois núcleos, nos Campi de Chapecó/SC e Erechim/RS. Os acadêmicos

1 Doutor em História. Professor adjunto da Universidade Federal da Fronteira Sul (UFFS), coordenador de área do Subprojeto de História (Campus Chapecó/ SC) do PIBID-UFFS. Contato: delcio.marquetti@uffs.edu.br

2 Doutora em História. Professora adjunta da Universidade Federal da Fronteira Sul (UFFS), coordenadora de área do Subprojeto de História (Campus Chapecó/SC) do PIBID-UFFS. Contato: isabel.gritti@uffs.edu.br.

${ }^{3}$ Doutor em História. Professor adjunto da Universidade Federal da Fronteira Sul (UFFS), coordenador de área do Subprojeto de História (Campus Chapecó/ SC) do PIBID-UFFS. Contato: renato.boy@uffs.edu.br 
participantes foram-se inserindo no cotidiano das escolas, conhecendo suas realidades e tomando parte na dinâmica das aulas de História, acompanhando-as e promovendo intervenções pontuais marcadas por debates atuais (Dia da Consciência Negra, Dia da Mulher) em consonância com o que dispõem a Lei de Diretrizes e Bases da Educação Nacional (LDB), a Base Nacional Comum Curricular (BNCC) e o Projeto Pedagógico do Curso de História. Em 2019, puderam participar, desde o início do ano letivo, dos planejamentos das escolas, propondo ações qualificadas que propiciem maior interação entre universidade e escola, e atendam aos objetivos do PIBID, no que diz respeito à formação desses futuros professores.

Palavras-chave: História. Formação de professores. Ensino de História.

\section{APRESENTAÇÃO DO PROGRAMA E ESCOLAS/BREVE HISTÓRICO/PRIMEIRAS INSERÇÕES}

O Programa Institucional de Bolsas de Iniciação à Docência (PIBID), que destina bolsas a estudantes de cursos de licenciatura na fase inicial de sua formação, vem sendo implementado, na Universidade Federal da Fronteira Sul (UFFS), no caso do Curso de História, desde o ano de 2011 (o Programa existe desde 2007, embora, em princípio, não contemplava as Ciências Humanas), atendendo, primeiramente, ao Edital 001/2011, publicado pela Coordenação de Aperfeiçoamento de Pessoal de Nível Superior (Capes).

Em 2018, as atividades tiveram início com a publicação, em $1^{\circ}$ de março, do Edital n. 7/2018, que apresentou mudanças importantes em relação aos editais anteriores. A elaboração dos subprojetos que compõe o Programa Institucional do PIBID da UFFS levou em conta as diferentes áreas do saber, contempladas nos seus cursos de licenciatura, abrangendo, em certos casos, uma única área, ou agrupando dois ou mais cursos em projetos 
interdisciplinares, sendo que, nesse caso, as licenciaturas que os compõe desenvolvem suas atividades de forma individualizada. Alguns subprojetos contam com mais de um núcleo, nos casos em que o curso é ofertado em mais de um dos campi da Universidade.

Foram elaborados nove subprojetos ${ }^{4}$, todos aprovados pela Capes, que iniciaram suas atividades em agosto de 2018, cujo prazo, de 18 meses, terminará em fevereiro de 2020. O Subprojeto de História, elaborado pelos campi de Chapecó/SC e Erechim/RS, levou em conta o disposto no Edital n. 7/2018 da Capes, bem como na Base Nacional Comum Curricular (BNCC), no Plano Nacional de Educação (PNE) e no Projeto Pedagógico do Curso (PPC).

Um dos objetivos do Programa é o de inserir os estudantes das licenciaturas nas escolas de Ensino Básico, espaço privilegiado de sua futura atuação, já nos primeiros anos de seu ingresso na graduação. O PPC de História ${ }^{5}$, em seus "Referenciais ético-políticos, epistemológicos e metodológicos", prevê que "A prática docente na escola básica será o objetivo principal desta formação, ainda que o currículo preveja, concomitantemente, a preparação para a atuação em outros espaços educativos e de pesquisa, bem como visa formar pesquisadores." (PROJETO..., 2013, p. 23).

Normalmente essa aproximação (e alguma atuação) do futuro licenciado no cotidiano da atividade escolar, só se dará quando o licenciando vai se aproximando da conclusão do curso, no momento de seu Estágio Curricular Supervisionado. A Capes manifesta a preocupação com a articulação entre teoria e prática necessária à formação do docente, e, em consonância com essa necessidade, o Curso de História pretende que "os saberes

\footnotetext{
4 São eles: Biologia; Educação no campo; Geografia; Interdisciplinar em Filosofia, História e Sociologia; Letras (Língua Espanhola e Língua Portuguesa); Matemática; Pedagogia e Química.

${ }^{5}$ Disponível em: https:/www.uffs.edu.br/atos-normativos/ppc/cclhch/2012-0002. Acesso em: 19 mar. 2019.
} 
produzidos na escola e na universidade possam se encontrar." (PROJETO..., 2013, p. 22). O Subprojeto de História compreende ambos, escola e universidade, como importantes espaços de produção de saberes.

O PIBID propicia ao futuro professor conhecer a realidade do espaço escolar, seu entorno e os sujeitos com os quais irá interagir depois de formado, como também o exercício da reflexão crítica sobre essa realidade. Busca perceber fragilidades da Educação Básica e assim formular, em conjunto com seus pares, propostas de superação criativa dos problemas observados. Nas últimas décadas no Brasil, um dos maiores investimentos que tem sido realizado, foi no sentido de se aperfeiçoar habilidades de escrita, leitura e fala de estudantes dos níveis Fundamental e Médio e também de nível superior, de forma a assegurar seus direitos de aprendizagem e desenvolvimento, em conformidade com o que preceitua o Plano Nacional de Educação (PNE) (BRASIL, 2018, p. 7).

O Subprojeto de História estruturou-se em dois núcleos, em Chapecó/SC e Erechim/RS. Uma das mudanças proporcionadas pelo Edital n. 7 em relação aos anteriores, diz respeito à quantidade de acadêmicos que compõem os núcleos, sendo 24 bolsistas e seis voluntários em cada núcleo. No caso de Chapecó, oito bolsistas e dois voluntários foram alocados na Escola de Educação Básica Prof. Nelson Horostecki, e os demais, 16 bolsistas e quatro voluntários, na EEB Saad Antonio Sarquis. Em Erechim, foram alocados na Escola de Educação Básica Dr. Sidney Guerra, oito bolsistas e dois voluntários, e na EEEM Professora Helvetica Rotta Magnabosco, oito bolsistas e dois voluntários.

Nas escolas, os "pibidianos" (como são denominados os acadêmicos participantes) são supervisionados por professores habilitados na área (o Edital n. 7 os designou "preceptores"), que também recebem bolsa mensal da Capes. Essa dinâmica coloca os professores que já atuam na Educação Básica na condição de 
importantes protagonistas do processo de formação dos novos profissionais da área, ao empregarem sua experiência profissional na orientação e auxílio que dedicam nas atividades que o subprojeto desenvolve diretamente no espaço escolar.

Em Chapecó, a escola Prof. Nelson Horostecki, localizada no centro da cidade, atende a mais de 1.000 alunos regularmente matriculados, nos níveis Fundamental (diurno) e Médio (diurno e noturno), e seu corpo discente apresenta grande diversidade socioeconômica. A escola Saad Antonio Sarquis atende a aproximadamente 800 estudantes nos níveis Fundamental (diurno) e Médio (diurno e noturno). Encontra-se localizada em bairro mais distante do centro, cuja comunidade é formada de trabalhadores e alguns pequenos empreendedores. $\mathrm{O}$ ensino noturno é frequentado em grande maioria por alunos trabalhadores e têm recebido estudantes estrangeiros (haitianos).

Em Erechim/RS, o Subprojeto de História atua na Escola Estadual de Ensino Médio Professora Helvética Rotta Magnabosco, situada no Distrito Industrial, e na Escola de Educação Básica Dr. Sidney Guerra, localizada no bairro Aldo Arioli. Ambas atendem uma média de 900 a 1.000 alunos dos níveis Fundamental e Médio. Suas comunidades escolares são compostas, em sua maioria, de trabalhadores e filhos de trabalhadores das regiões mais afastadas do centro da cidade.

O Subprojeto articula-se com a comunidade escolar e seus atores sociais (gestores, professores, estudantes, familiares dos estudantes), à medida que toma esse espaço como lugar de intervenção e de produção de saberes, em conexão direta com a academia e sua dinâmica formativa, que passa pelas mais diversas atividades previstas no PPC de História.

Em uma das escolas onde o Subprojeto de História atua, ao observar a realidade escolar de forma ampla, uma pibidiana registrou que há a preocupação com as condições sociais e familiares dos estudantes para além dos muros da escola, 
“(...) principalmente com os que possuem algum problema familiar, o que, consequentemente, afeta o aluno no desempenho escolar." (Victoria Artigas Pause. Escola Saad Sarquis/Chapecó). Pensar a educação é pensar conteúdos curriculares associados às demandas sociais "Assim, é notável que a escola tenta que ajudar e criar jeitos de lidar com os problemas cotidianos de uma escola pública da melhor maneira., prossegue a pibidiana.

Conhecimento histórico e formação do professor, no Curso de Licenciatura em História da UFFS, concatenam-se do início ao fim, sem privilegiar espaços estanques de debate, o que representaria o risco de pensarmos um profissional dividido entre o conhecimento que é da natureza de sua ciência, de um lado, e os saberes do campo didático-pedagógico, de outro.

É essa concepção de iniciação à docência e formação de professores de História que norteia o Subprojeto de História, na compreensão de que o conhecimento não se constrói de forma unilateral, mas em redes que perpassam os mais diversos espaços e sujeitos sociais, e que não se dá de forma exclusiva no âmbito da academia.

A dinâmica do Subprojeto propõe o constante diálogo entre esses dois espaços de atuação, cuja carga horária dos acadêmicos se divide entre atividades na escola e atividades na Universidade. Na visão de um dos pibidianos, essa dinâmica é importante, pois

"As atividades desenvolvidas no Programa, tanto na Escola de Educação Básica Professor Nelson Horostecki quanto na Universidade foram grande importância (...), pois elas nos inserem na rotina de um professor da escola básica e nos capacitam através de leituras e debates, propiciando uma ótima experiência para formar o nosso caráter como futuros professores que estamos estudando para nos tornar." (Lucas Wazlawick do Carmo. Escola Nelson Horostecki / Chapecó). 
Nesse sentido, em consonância com o previsto nos objetivos da Capes: "Contribuir para a articulação entre teoria e prática necessárias à formação dos docentes, elevando a qualidade das ações acadêmicas nos cursos de licenciatura." (CAPES, 2018), busca-se a superação da (falsa) dicotomia teoria-prática e do distanciamento histórico universidade-escola.

\section{RELATOS DAS EXPERIÊNCIAS: CHAPECÓ/SC}

As atividades (relativas ao Edital n. 7/2018) tiveram início, de fato, em setembro de 2018, depois de um período de organização de documentação e de cadastros na Plataforma SCBA ${ }^{6}$. Em Chapecó, e, em Erechim, as primeiras visitas às escolas ocorreram no mês de setembro dias 11 (Prof. Nelson Horostecki) e 12 (Saad Sarquis), dias 14 (Helvética Magnabosco) e 19 (Sidney Guerra). Nesses encontros, foram apresentados históricos das escolas, perfis socioeconômicos dessas comunidades escolares (no caso, alunos e familiares), bem como suas estruturas de funcionamento, suas dependências e os Projetos Políticos Pedagógicos.

O lançamento oficial do Programa ocorreu em dia 24 de setembro, nas dependências da UFFS, Campus Chapecó, com transmissão aos demais campi que aderiram ao Programa, via videoconferência. O evento contou com a presença da profa. Dra. Janaína Damasco Umbelino ${ }^{7}$, que proferiu a palestra "PIBID e formação de professores: aprender a atividade docente". O evento reuniu acadêmicos, professores supervisores das escolas e coordenadores dos subprojetos.

A professora Janaína Damasco Umbelino expôs a trajetória do Programa, que parte de uma preocupação da Lei de Diretrizes

\footnotetext{
6 Sistema de Concessão de Bolsas e Auxílios/Capes.

7 Universidade Estadual do Oeste do Paraná (UNIOESTE) - Francisco Beltrão/PR.
} 
e Bases da Educação Nacional (LDB) com a melhora da qualidade da Educação Básica, que passa, de forma acentuada, pela formação dos professores, e enfatizou a organização do FORPIBID e do movimento "Fica PIBID”. Na percepção de uma das pibidianas,

"Com um discurso temático pertinente, [a conferencista] destacou a mobilização de bolsistas e coordenadores para o movimento "Fica PIBID", ocorrido em 2016, com objetivo de manter o programa de incentivo à docência aos alunos de licenciatura. Ressaltou que o Programa fortalece a formação dos graduandos com experiências metodológicas, tecnológicas e práticas docentes." (Maiara de Oliveira Trevisan. Escola Prof. Nelson Horostecki/Chapecó).

Os dados que embasaram as reflexões propostas pela professora Janaína foram de suma importância para os acadêmicos que, sendo das fases iniciais do Curso, muitos deles vêm agora tendo seu primeiro contato com o Programa. São poucos os que conheceram o PIBID enquanto foram estudantes do ensino regular.

Em Chapecó, os pibidianos foram sendo inseridos no cotidiano das escolas e em sua rotina de atividades, estudando documentos e legislação pertinentes, como Projeto Político Pedagógico (PPP), levantamento de Perfil socioeconômico da comunidade escolar, estudando a LDB e outros documentos. Em seguida, passaram a acompanhar os professores supervisores em suas aulas e demais atividades, observando e tomando parte em planejamentos de aulas e atividades mais gerais das escolas, como conselhos de classe e reuniões pedagógicas. A partir de seus planejamentos, os professores supervisores desafiaram os pibidianos a promoverem intervenções em suas aulas e demais atividades da escola. Toma-se como exemplo, no mês de novembro, ações relativas ao Dia Nacional da Consciência Negra, para o qual planejaram aulas sobre o tema. Relatou uma acadêmica 
"Chegando o dia 20/11, dia de nossa intervenção, eu e minha dupla acompanhamos outros dois colegas do Neabi, no terceiro ano, durante o primeiro período da manhã. Apresentamos conceitos gerais acerca do Dia da Consciência Negra e vídeos, um deles do canal Futura sobre Identidade Negra e outro do TEDx Talks, com a professora Lia Vainer Schucman doutora pela USP em Psicologia Racial, sobre beleza negra. No fim da aula, entregamos corações para os alunos escreverem seus preconceitos e guardarem para si, e depois de um tempo olharem e ver se ainda tem aqueles sentimentos. Nesse dia, foi muito bacana interagir com o os alunos estando na frente da sala, apesar do curto período, e a turma foi atenciosa com as atividades, o que nos deu um resultado positivo da intervenção." (Victoria Artigas Pause. Escola Saad Sarquis/Chapecó).

Além dessas primeiras experiências docentes, foram também envolvidos em gincanas, competições e demais ações que as escolas têm previstas em seus calendários anuais. Como resultado, os pibidianos criaram um olhar de quem agora se aproxima da escola não apenas como um estudante, mas como alguém que é desafiado a pensá-la em sua complexidade e organicidade, percebendo que o "trabalho do professor" ultrapassa, em muito, aquilo que se faz no espaço dos 45 ou 50 minutos em que o aluno "assiste" sua aula.

"Já nos primeiros encontros, me foi possível enxergar a escola muito além do aspecto do letramento e formação de grau, percebendo então ela como um lugar incumbido de promover o desenvolvimento educacional assim como social, permitindo a evolução de vários aspectos da vida de uma criança/jovem através da educação. Também pude compreender melhor o que é o trabalho do professor, algo que me encantou muito, este vai muito além da sala de aula, é desenvolvido com preocupação, carinho, empatia

${ }^{8}$ Núcleo de Estudos e Pesquisas Afrobrasileiros e Indígenas, UFFS/Chapecó. 
e consciência, sempre pensando no melhor para o aluno e seu progresso no futuro. Penso que ter consciência desses aspectos é essencial para a vida de um professor, logo posso dizer que o PIBID vai muito além de uma bolsa, ele é um despertar para o professor iniciante." (Milena Caregnato, Escola Saad Sarquis/Chapecó).

Sobre a experiência de estar inserido no ambiente escolar, encontramos relatos de pibidianos que mostram um verdadeiro deslumbramento com os primeiros contatos com o trabalho docente. Nos depoimentos a seguir, recortamos algumas percepções muito positivas dos graduandos envolvidos no subprojeto:

"De um modo geral, as práticas exercidas no PIBID/História têm sido de grande utilidade para minha formação acadêmica e formação pessoal. Apesar desse não ser o meu primeiro contato com o projeto, esta tem sido uma experiência impar, visto que a escola, o público e os colegas são diferentes. Aliar teoria e prática contribui muito no aprendizado, poder aplicar o que aprendemos durante a graduação e ver quais os prós e os contras, agregam experiências indispensáveis. Estar inserido no ambiente escolar é incrivel para um acadêmico, pois garante uma proximidade com o aluno, com a universidade e a escola. Constrói um trabalho conjunto, aliando interesses na medida do possível. Acredito que a dinâmica do subprojeto está caminhando bem, as adaptações acontecem conforme a necessidade." (Mateus Eduardo Borsa, Escola Saad Sarquis/Chapecó).

O depoimento seguinte foi retirado de outra escola, do mesmo subprojeto, também registrando um encantamento inicial com o subprojeto:

"Concluindo, de minha parte posso afirmar que os meses trabalhados no ano de 2018 foram de um aprendizado inesquecivel, de um ganho de experiência da mesma forma de esclarecimento do que realmente é uma rotina de um 
docente, de sua comunicação e convívio com os membros da escola, não sendo exclusivamente uma rotina de idas na escola para realização de suas aulas, mas sim, de uma soma de alfazeres que demandam de um professor." (Vinícius Vargas, Escola Escola Prof. Nelson Horostecki/Chapecó).

No núcleo de Erechim, uma importante constatação, que já vem sendo observada nos anos anteriores, diz respeito ao pouco conhecimento da realidade escolar, oferecida pelo curso. $\mathrm{O}$ contato dos futuros educadores e educadoras ocorre basicamente nas disciplinas de estágio integrantes da grade curricular. Destacam os participantes do Programa a importância desse "conhecer" a vivência cotidiana da sala de aula e da escola. Demonstram ansiedade por esse contato, especialmente o da sala de aula, por meio das intervenções e oficinas realizadas ao longo do Programa.

Entretanto, o deslumbramento resultante dessas primeiras experiências docentes não impediu os pibidianos de perceberem a realidade do espaço escolar, sua dinâmica e necessidades de ajustes. Numa das atividades envolvendo o Projeto Político Pedagógico (PPP) da escola Nelson Horostecki, uma graduanda relatou não apenas a inserção do PIBID nessa tarefa, mas também a possibilidade aberta pela professora supervisora para que os pibidianos pudessem participar diretamente desse processo:

Chegando ao final da discussão sobre o PPP, houve a necessidade em reformular a pesquisa elaborando uma nova análise referente às respostas dos alunos, para fins de utilização ao PPP do ano de 2019. Uma atividade proposta pela professora supervisora Dircema dos Santos Sulsbach e projetada pelos alunos pibidianos, que apresentaram o novo Projeto Político Pedagógico no início do novo semestre letivo. Sendo assim, o dia 09 de outubro foi destinado para a organização dos questionários utilizados na pesquisa. (Maiara de Oliveira Trevisan. Escola Prof. Nelson Horostecki/Chapecó). 
Essa visão crítica em relação também às dificuldades encontradas pode ainda ser percebida no que diz respeito à estruturação e início um tanto tardio do PIBID no ano letivo de 2018, no qual os pibidianos entraram nas escolas apenas no segundo semestre:

"Dentre as atividades desempenhadas, confesso que houveram dificuldades para nossa inserção em meio ao andamento das atividades e dos conhecimentos dos alunos, devido à nossa entrada invasiva efetuada na metade final do ano letivo, praticamente, nos três últimos meses de desempenho das atividades. Nesse sentido, dos quatro bimestres presentes no ano escolar da escola, apenas no último é que de fato estivemos presentes e realizamos atividades de acompanhamento de turma, realização de atividades e participação nas mesmas do início ao fim do mesmo. Esse aspecto aliás, foi uma autocrítica realizada por nossos professores coordenadores quando de nosso terceiro e último encontro na universidade em dezembro de 2018, e que foi ponto de discussão e concordância por parte de praticamente todos os bolsistas, voluntários e professores-supervisores, tanto da EEB Saad Antônio Sarquis como também da EEB Nelson Horostecki que fizeram-se presentes." (Cassiano Felipe Possel Greter, Escola Saad Sarquis).

E, entre o encantamento da primeira experiência docente e a abordagem crítica em relação ao início das atividades, há também reflexões sobre a importância do projeto na formação do graduando e das possibilidades abertas para o PIBID no início desse segundo semestre do Projeto:

"O PIBID é um programa de extrema necessidade a cursos de licenciatura como o nosso, e haver movimentos de resistência e luta por sua manutenção, de modo que lutar-se-á pela sua continuidade de modo mais íntegro possível, e que o mesmo continue rendendo bons frutos tanto as escolas ao qual vincula-se, como também as instituições de ensino 
superior no qual está fundamentado. No decorrer desse ano [2019], acompanharemos de modo integral todo o ano letivo de nossa instituição, de modo a estarmos mais familiarizados ao programa, aos alunos, e munidos de ainda mais conhecimento acadêmico, do qual, como evidenciado, já valemo-nos em relação as atividades, e certamente o contrário também, levando nossas experiências nas instituições de Educação Básica para o meio da academia. O PIBID prossegue!" (Cassiano Felipe Possel Greter, Escola Saad Sarquis).

\section{RELATOS DAS EXPERIÊNCIAS: ERECHIM/RS}

As ações do PIBID são diversas e são planejadas a partir das demandas solicitadas pelas comunidades escolares. São exemplos algumas ações levadas a cabo em subprojetos de editais anteriores.

Apresentamos aqui umas das várias atividades interessantes, desenvolvida no núcleo de Erechim, entre os anos de 2015 e 2016. Nos encontros semanais, que ocorreram nas escolas e nas dependências da UFFS, procurava-se concretizar os objetivos propostos pelo Subprojeto de História, discutindo a formação de professores de História, o ensino de História e suas metodologias, bem como os principais conceitos da Ciência histórica, tudo isso articulado com a LDB e demais legislações que estabelecem as diretrizes ligadas aos temas referidos. Em meio a essas discussões, de cunho mais teórico, ocorreram reflexões que partem das observações realizadas pelos pibidianos em suas vivências nas escolas.

Isso tudo culminava com a preparação de intervenções, solicitadas pelos professores supervisores das escolas, enquanto demandas surgidas nas reuniões pedagógicas. Algumas dessas intervenções se deram na forma de oficinas que envolveram todos os alunos da escola. São exemplos as oficinas realizadas a partir das temáticas: a) Direitos Humanos, e, b) História da África e 
Indígena. Essas temáticas partem dos Temas Transversais definidos pelos Parâmetros Curriculares Nacionais, como a história e a cultura indígena, direitos humanos, educação ambiental e a cultura afro-brasileira.

Dentre as várias atividades desenvolvidas por meio de oficinas, a que discutiu história da África e cultura afro-brasileira e indígena foi construída a partir dos dados de uma pesquisa realizada sobre a temática. A vivência cotidiana dos bolsistas como acadêmicos na universidade e a observação do cotidiano escolar provocou o grupo para um estudo aprofundado da questão. Outro elemento importante nesse debate foi a implementação das Leis n. 10.639/2003 e n. 11.645/2008, que tornou obrigatória a inclusão no currículo escolar a História da África, a Cultura Afro-brasileira e a Cultura Indígena.

Para melhor fundamentar a realização das oficinas, realizamos uma pesquisa (espécie de enquete) junto aos professores de História e alunos das duas escolas da rede pública em que o PIBID/História estava presente, e com os acadêmicos dos cursos de Ciências Sociais, Agronomia e Pedagogia da UFFS. A análise das respostas foi realizada a partir das discussões existentes em torno da Educação Histórica. A pesquisa e o estudo teórico tiveram o intuito de possibilitar a construção de uma metodologia que possibilitasse abarcar a totalidade das questões respondidas pelos 70 alunos e 15 professores da rede pública e pelos 70 acadêmicos integrantes de duas licenciaturas e de um bacharelado.

Não é possível aqui, nem é o propósito, discutir na totalidade as respostas dos entrevistados. Mas a análise das seis questões objetivas e uma descritiva revelou algumas informações e concepções que trouxeram preocupação ao grupo, que entendeu ser urgente discuti-las.

A pesquisa revelou opiniões fundamentadas em preconceitos, decorrentes do não conhecimento da História e da cultura africana e indígena. A principal fonte de informação sobre essas 
temáticas eram os programas de TV, e em segundo lugar, muito distante do primeiro, os livros didáticos. Diante desses dados, não surpreende a resistência dos professores em levar História da África e indígena para sala de aula. No caso dos professores o fato de terem cursado uma licenciatura onde essas duas importantes culturas ainda não eram enfatizadas no currículo do curso, ajuda a compreender a desinformação, inclusive entre os acadêmicos entrevistados, especialmente, nesse caso, os das licenciaturas.

Depois da tabulação, os dados foram dispostos graficamente e, então, analisados. A partir dessas informações é que as oficinas foram pensadas. $\mathrm{E}$ foram várias as atividades desenvolvidas nas escolas com alunos e professores. A participação foi expressiva e a avaliação das mesmas, positiva. Trabalhamos com vídeos, poesias, músicas, com alimentação, com vestimenta. Todas elas bastante lúdicas e criativas, e exigiam a participação efetiva dos seus integrantes.

Embora tivéssemos um conhecimento empírico da existência do preconceito em relação à cultura africana e indígena, a realização da pesquisa nos deu elementos consistentes de análise e possibilitou que trabalhássemos com relativa segurança na elaboração das oficinas, com o objetivo de auxiliar na desconstrução desses estereótipos e preconceitos, com raízes profundas e bastante dispersas.

As oficinas foram realizadas com os Anos Iniciais do Ensino Fundamental. Embora o PIBID/História (Erechim) não tenha seu olhar central nos Anos Iniciais, todas as vezes que solicitados pela Escola foram realizadas atividades com os estudantes dessas faixas etárias. E foram várias as nossas intervenções nessa fase escolar, o que por si só revela a importância dessa etapa estudantil e do Programa de Iniciação à Docência de História.

As atividades planejadas e desenvolvidas envolvendo a cultura indígena teve como tema central a arte produzida pelas etnias Kaingang e Guarani. A escolha recaiu sobre a produção 
artística desses grupos por se fazerem presentes no cotidiano das crianças, que os encontram nas ruas da cidade vendendo seu artesanato, que é também seu trabalho. Esses indígenas habitam nossa região, e são várias as reservas indígenas presentes no entorno, sendo fácil o seu acesso.

Os Kaingang são numericamente superiores aos Guarani na região do núcleo Erechim do subprojeto do PIBID/História, estando presentes no cotidiano dessa região.

\section{PROJEÇÕES PARA 2019}

Para o ano letivo de 2019, o PIBID/História se fez presente no planejamento anual das escolas onde atua, contribuindo com as atividades previstas no calendário. Entre as atividades já planejadas, estão propostas a inserção dos pibidianos nos trabalhos sobre o Dia Internacional da Mulher, Dia da Família, Feiras Culturais, visitas de campo, questão ambiental, entre outras.

Há ainda a proposta de aproximação dos estudantes do Ensino Médio junto ao curso de Licenciatura em História, não apenas nos espaços da universidade, mas também no contato com os Laboratórios mantidos pelos professores do curso. Isso poderá permitir aos estudantes das escolas nas quais o PIBID/História está atuando construir uma visão mais complexa e variada do trabalho com ensino e pesquisa em História na UFFS.

O ano de 2019 reserva ainda alguns desafios, mas as expectativas são muito animadoras, em especial, por podermos perceber nos relatos de alguns pibidianos o entusiasmo com o trabalho docente e a compreensão da importância do PIBID/História, tanto nas escolas onde se faz presente, como também no processo de graduação e formação profissional do pibidiano:

Sendo assim, esse primeiro contato que tive com a escola, antes dos estágios, foi de suma importância, pois nos integra a 
uma prática que não temos tão facilmente. E também, me sinto agradecida por fazer parte desse projeto que luta para continuar e ajuda a tantos jovens a saber se suas escolhas foram corretas em escolher uma licenciatura. E com minha participação, pude ter essa oportunidade de saber se realmente fiz a escolha certa e descobri que sim, a profissão pode ser desvalorizada, mas nosso trabalho está muito distante disso. (Victoria Artigas Pause. Escola Saad Sarquis/ Chapecó).

Para encerrar, utilizamo-nos aqui das palavras do pibidiano Cassiano Felipe Possel Greter, com a qual concordamos: "O PIBID continua!”. E, com ele, continuaremos buscando a valorização da formação do licenciado em História na UFFS.

\section{REFERÊNCIAS}

BRASIL. Ministério da Educação. Base Nacional Comum Curricular. 2018. Disponível em: basenacionalcomum.mec.gov.br/. Acesso em: 7 abr. 2019.

BRASIL. Ministério da Educação. Plano Nacional de Educação. O Plano Nacional de Educação (PNE) determina diretrizes, metas e estratégias para a política educacional no período de 2014 a 2024. Disponível em: pne.mec.gov.br/. Acesso em: 7 abr. 2019.

COORDENAÇÃO DE APERFEIÇOAMENTO DE PESSOAL DE NÍVEL SUPERIOR (CAPES). Edital 07/2018/Capes. Programa Institucional de Bolsa de Iniciação à Docência (PIBID): chamada pública para apresentação de propostas Edital n. 07/2018: Processo n. 23038.001433/2018-98. Disponível em: https://www.capes.gov.br/ images/stories/.../01032018-Edital-7-2018-PIBID.pdf. Acesso em: 2 abr. 2019.

PROJETO PEDAGÓGICO DO CURSO DE HISTÓRIA DA UFFS. 2013. Disponível em: https://www.uffs.edu.br/atos-normativos/ppc/ cclhch/2012-0002. Acesso em: 19 mar. 2019. 
